\title{
Serum Level of Follistatin in Patients with Scarring and non Scarring Acne Vulgaris
}

A.I.El-Taweel ${ }^{1}$, A.I.Mustafa ${ }^{1}$, W.A.Abdul Haleem ${ }^{2}$ and O.M.Abd El-Motaleb ${ }^{1}$

${ }^{1}$ Dermatology, Venereology \& Andrology Dept., Faculty of Medicine, Benha Univ., Benha, Egypt

${ }^{2}$ Clinical and Chemical Pathology Dept., Faculty of Medicine, Benha Univ., Benha, Egypt

\begin{abstract}
Acne vulgaris is a chronic cutaneous inflammatory disorder. Four factors play vital roles in acne pathophysiology: hyperseborrhea, altered keratinization of the pilosebaceous duct, propionobacterium acnes (p. acnes) and inflammation. to assess serum level of follistatin in patients with scarring and non scarring AV aiming at understanding the pathogenesis of post acne scars. serum FST level was assessed in 60 acne patients (30 non scarring patients - 30 scarring patients) and 20 apparently healthy subjects as control with matched age and sex. Every patient included in the study was subjected to detailed history taking, complete general and dermatological examination and assessment of serum level of FST by using commercial ELISA kits.AV, non scarring and scarring patients had significantly higher frequency with positive family history, sun exposure and excess stress when compared to control group ( $\mathrm{p}$ value $0.010,0.005$ and $<0.001$ respectively. However, No significant differences were found in risk factors between acne groups. serum FST level was significantly lower in patients with acne than control group although its level was significantly lower in scarring acne patients than non scarring patients.
\end{abstract}

E-Mail:Omnia@yahoo.com

Keywords: Follistatin, Acne Vulgaris, Scarring.

\section{Introduction}

Skin inflammation vulgaris (AV) will be An cutaneous incessant incendiary confusion for mind boggling pathogenesis. Four variables assume indispensable parts for skin break out pathophysiology: hyperseborrhea, modified keratinization of the pilosebaceousconduit ,propionobacterium acnes (p. Acnes). Emerging on the face, midsection and once again [1].

Skin break out may be those the vast majority common skin ailment in the world, influencing $85 \%$ about youths Furthermore over 10\% of Grown-ups [2].

Skin break out scars would a standout amongst those The greater part as a relatable point muddling of skin inflammation vulgaris that influence something like 30\% of the individuals with direct Also extreme skin inflammation vulgaris. It particulary convolute nodulocystic skin break out, skin break out conglobate What's more skin break out fulminans, it might additionally entangle childish skin break out. Scaring alludes on An stringy procedure to which new collagen will be laid down with mend An full thickness damage [3].

There need aid separate clinical sorts of skin break out scars relying upon if the abnormal recuperating will be connected with abundance collagen affidavit or passing In the webpage of the skin break out lese greatness the atrophic scars need aid those practically normal kind What's more it may be ordered Previously, will ice pick scars, car scars and rolling scars which need aid wider over those ice pick scars. Hypertrophic scars which need aid lesquerella regular and arranged done on \{hypertrophic scars which remains inside the first edge of the wound, keloid scars that might structure scar tissue outside the wound outskirts [4].

Follistatin (FST) is a paramount administrative protein, a common adversary for transforming development factor-b relativesactivin What's more myostatin. Those different biologic parts of the activin Furthermore myostatin indicating pathways settle on FST An guaranteeing restorative focus for treating mankind's maladies exhibiting inflammation, fibrosis, What's more muscle issue. FST may be vital to life; reduction for work mutants bite the dust right away after conception [5].

Follistatin need a number from claiming putative physiological roles, including managing pituitary fshcreation, ovarian follicle development , spermatogenesis, liver homeostasis, wound repair shed, Also light of incendiary jolts. Numerous isoforms for FST need aid prepared starting with those FST gene (FST303 ,FST288 Also FST315) [6].

Keratinocytes overexpressing activin-A fortified burgeoning of dermal fibroblasts, suggesting a paracrine part with Push fibroblast proliferation, Furthermore upgrade collagen creation over scar fibroblasts. Activin-A is An intense inducer of fibroblast actuation. Follistatin needed no impact on the outflow for extracellular grid (ECM) parts straightforwardly Yet blocked those activininduced expands. Follistatin antagonizes the impact for activin-A Eventually Tom's perusing tying willactivin itself, rendering it dormant [7].

Follistatin need mostly been depicted Similarly as an mitigating part hindering test prompted hypersensitive asthma Furthermore provocative gut ailment Previously, mice Toward blocking activin a [8]. However, its part done skin break out Also skin break out scar pathogenesis might have been not Awhile ago investigated.

Those point from claiming this ponder might have been will survey serum level of follistatin Previously, patients for scarring What's more non scarring av pointing toward understanding the pathogenesis from claiming post skin break out scars.

\section{Patients and methods}

This prospective body of evidence control examine might have been directed for 30 patients suffice starting with non-scarring skin inflammation vulgaris, 30 patients suffice from scarring skin inflammation vulgaris. To addition, 20 clearly sound people might have been decided Likewise control bunch. Patients were recruited starting with the outpatient facility from claiming dermatology and Andrology division of Benha school healing centers. 
The study might have been endorsed by the nearby morals panel once research directing, including mankind's subjects of Benha staff of drug. Educated assent might have been acquired starting with every unique in front of example accumulation.

\section{1 Incorporation Criteria}

- Helpful tolerant $\geq 15$ Furthermore $\leq 45$ a considerable length of time of age.

- Clinically commonplace skin inflammation vulgaris lesions What's more post skin break out scars.

- Separate degrees about seriousness of skin break out vulgais as stated by worldwide skin break out evaluating framework. $\cdot$ distinctive sorts about scarring skin inflammation vulgaris.

\section{2 Exclusion criteria}

- Patients for At whatever dermatological states on the face that Might meddle for clinical assessment for example, rosacea What's more perioral dermatitis.

- female subjects who were pregnant What's more lactating females.

- utilization of estrogens for under 12 weeks first contemplate passage.

- In female liable required historical backdrop from claiming hirsutism, polycystic ovaries Furthermore clinically noteworthy menstrual irregularities.

- Patients for hitory of systemic ailments Concerning illustration diabetes mellitus, chronic liver maladies Also incessant kidney ailments.

- the sum patients were subjected will full history taking, complete clinical examination What's more serum FST by catalyst loved immunosorbent test (ELISA) unit.

\section{3 Statistical dissection}

Those gathered information might have been revised, coded, tabulated Furthermore presented with An pc utilizing measurable bundle for social science (IBM corp. Discharged 2011. IBM SPSS facts for Windows, form 20. 0 . Armonk, NY: IBM corp. ). Information were introduced Furthermore suitableness dissection might have been finished as stated by those kind for information got for every parameter. Mean, standard deviation $( \pm$ SD) to numerical information. Recurrence Furthermore rate of non-numerical information. Shapiro test might have been finished on test those typicality for information appropriation. Critical information might have been acknowledged to be nonparametric. Learner t test might have been used to evaluate those Factual hugeness of the Contrast between two consider aggregation intends. To the correlation of the three groups' means, restricted examination of fluctuation (ANOVA) might have been utilized. Chi-Square test might have been used to analyze those association the middle of two qualitative variables. Fisher's correct test: might have been used to analyze the relationship between two qualitative variables The point when the expected number will be less 5 to more than $20 \%$ of units.

\section{Results}

The present study included 60 patients with AV (30 non scaring, 30 scarring), and 20 healthy control groups. Demographic and anthropometric data in all studied groups in Table (1).

Table (1) Demographic and anthropometric data in all studied groups.

\begin{tabular}{|c|c|c|c|c|c|}
\hline & & \multirow{2}{*}{ ControlN=20 } & \multicolumn{3}{|c|}{ Acne Vulgaris } \\
\hline & & & TotalN $=60$ & NonscarringN=30 & ScarringN=30 \\
\hline \multirow{4}{*}{ Age (years) } & Mean & 20.7 & 22.7 & 21.5 & 23.8 \\
\hline & \pm & \pm & \pm & \pm & \pm \\
\hline & $\overline{S D}$ & 5.4 & 5.7 & 5.7 & 5.5 \\
\hline & $\mathrm{P}^{1}$ & - & $0.128^{\mathrm{T}}$ & $0.608^{\mathrm{T}}$ & $0.159^{\mathrm{T}}$ \\
\hline \multirow{7}{*}{ Female } & $\mathrm{P}^{2}$ & - & - & \multicolumn{2}{|c|}{$0.122^{\mathrm{T}}$} \\
\hline & $\mathrm{N}$ & 14 & 35 & 15 & 20 \\
\hline & $\%$ & $70 \%$ & $58.3 \%$ & $50 \%$ & $66.7 \%$ \\
\hline & $\mathrm{N}$ & 6 & 24 & 14 & 10 \\
\hline & $\%$ & $30 \%$ & $40 \%$ & $46.7 \%$ & $33.3 \%$ \\
\hline & $\mathrm{P}^{1}$ & - & $0.395^{\mathrm{C}}$ & $0.210^{\mathrm{C}}$ & $0.804^{\mathrm{C}}$ \\
\hline & $\mathrm{P}^{2}$ & - & - & \multicolumn{2}{|c|}{$0.243^{\mathrm{C}}$} \\
\hline \multirow{5}{*}{ BMI $\left(\mathrm{kg} / \mathrm{m}^{2}\right)$} & Mean & 24.9 & 24.4 & 24.1 & 24.7 \\
\hline & \pm & \pm & \pm & \pm & \pm \\
\hline & $\overline{S D}$ & 3.2 & 3.7 & 3.5 & $\overline{4}$ \\
\hline & $\mathrm{P}^{1}$ & - & $0.603^{\mathrm{T}}$ & $0.448^{\mathrm{T}}$ & $0.866^{\mathrm{T}}$ \\
\hline & $\mathrm{P}^{2}$ & - & - & \multicolumn{2}{|c|}{$0.509^{\mathrm{T}}$} \\
\hline
\end{tabular}

SD, standard deviation; T, Student t test; $\mathrm{C}$, chi square; P1, comparison of total cases, non scarring, scarring versus control; p2, comparison of non scarring versus scarring acne.

$\mathrm{AV}$, non scarring and scarring patients had significantly higher frequency with positive family history, sun exposure and excess stress when compared to control group ( $\mathrm{p}$ value $0.010,0.005$ and $<0.001$ respectively. 


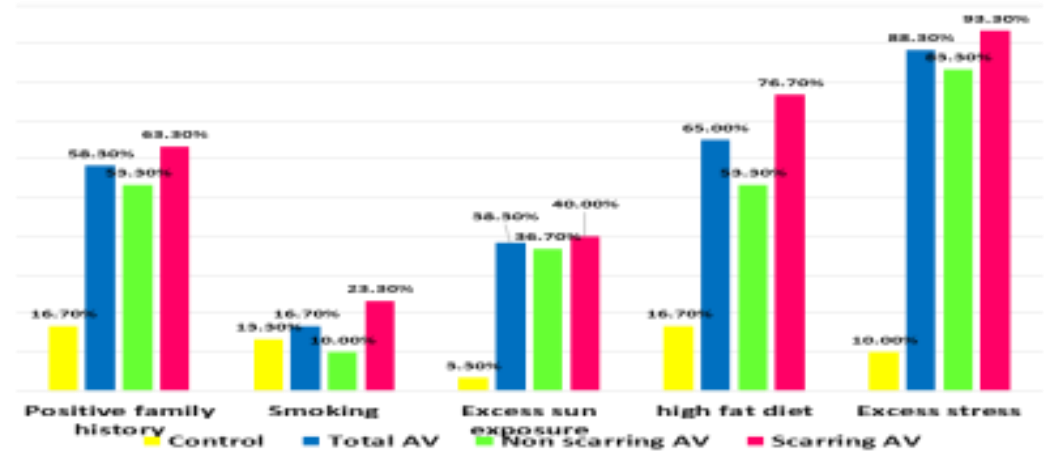

Fig (1) Bar chart for risk factors for AV in all studied groups.

The serum level of follistatin in AV patients (scarring and non scarring) is significantly lower when compared to control group. In addition, patients with post acne scars showed significantly lower serum follistatin level when compared to non scarring acne patients. Fig (2).

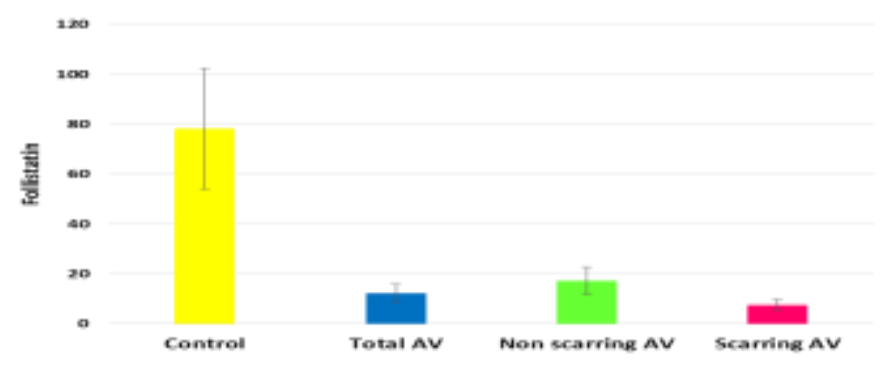

Fig (2) Bar chart for serum follistatin level in all studied groups.

\section{Discussion}

Skin inflammation vulgaris is a multifactorial incendiary malady of the pilosebaceous follicle, follicular hyper keratinization, increased sebum creation ,proliferation for propionibacterium acnes inside the follicle , and discharge for incendiary mediators On of the skin help those improvement about skin break out [9].

Could reasonably be expected results for incendiary skin break out lesions are post skin break out scars which might make significant passionate Also mental trouble. Minor skin break out scars camwood happens for dependent upon $95 \%$ for patients Also huge scarring to best $22 \%$, skin break out scarring might make Possibly atrophic alternately hypertrophic. Atrophic skin break out scars would further subdivided morphologically under boxcar, ice pick, or rolling scars [10].

Follistatin is An multifunctional administrative protein. It need An part over directing inflammation, fibrosis, Also tissue repair shed [5].

Investigations formerly uncovered that follistatin restrain keratinocyte hyperproliferation ,[11], decline sebaceous organ lipid handling [12] Also regulate intrinsic safe reactions [13] created by microbial colonization of $p$. Acnes [14]. That affirm this study that recognized that serum level of follistatin in skin inflammation vulgaris groups, (scarring and non scarring subgroups) is altogether easier The point when contrasted with control gathering.

Follistatin, modifies those incendiary cytokine cascade, Furthermore diminishes those seriousness of the resulting incendiary reaction. Activina fortifies immunizer generation by $\mathrm{b}$ units and the improvement for administrative $t$ units. Creation for activin a Throughout incendiary reactions fortifies fibrosis Furthermore tissue remodelling, Furthermore follistatin inhibits these activities about activin An. Those regulation from claiming activin Eventually Tom's perusing follistatin might representable a critical restorative target to the regulation Furthermore improvement for incendiary Also fibrotic issue. [15], Overexpression of follistatin in the epidermis reasons An solid delay for granulation tissue creation Furthermore wound re-epithelialization.

Aoki and Kojima [16], Activin-Follistatin framework may be an intricate regulatoy framework that controls different cell division capacity. And essential part Previously, organogenesis , recovery Furthermore tissue fibrosis of the liver, pancreas,kidney and lung.

Hu"bner et al. [17]. They exhibited an expanded incitement for activin-A statement inside $24 \mathrm{~h}$ then afterward injury, which stayed helter skelter until the limit of the repair shed transform. Transgenic mice, which overexpress those activin-A subunit particularly in the 
epidermis, bring epidermal hyperthickening and dermal fibrosis [17]. After skin injury, these mice indicate improved granulation tissue structuring with solid affidavit from claiming ecm The following the hyperproliferative keratinocytes.

Toward contrast, decreased granulation tissue framing and Subsequently Postponed recuperating were watched in mice overexpressing those activin antagonist, follistatin, in the epidermis [17]. Comes about of the present contemplate uncovered that scarring aggregation indicated essentially bring down follistatin when contrasted with non scarring assembly that the thing that might have been underpinned via past effects.

C sensitive protein (CRP) may be proportionally correlates of the seriousness for incendiary skin inflammation vulgaris. Its vicinity over av might help those group defenses against p. Acnes and also to tissue harm through its Different movements of the included resistant phones and incendiary mediators [18]. Serum follistatin focuses in people gives the idea should parallel serum ctouchy protein levels [19]. Effects of these investigation mean that follistatin may be proportionally correlates of the seriousness for av which alienate the come about from claiming available investigation.

\section{Conclusion}

From the results of the present study, it is concluded that, serum FST might play a negative role in acne scar pathogenesis. Morever, it could be considered a biomarker for early predicting the liability of acne patient to develop scars with high sensitivity, specificity and accuracy rate.

\section{References}

[1] H. C. Williams, R. P. Dellavalle, and S. Garner, "Acne vulgaris," Lancet, Vol. 379 (9813), PP. 361-372, 2012.

[2] E. J. M. Taylor, Y. Yu, J. Champer, and J. Kim, "Resveratrol demonstrates antimicrobial effects against Propionibacterium acnes in vitro," Dermatol. Ther. (Heidelb), Vol. 4(2), PP. 249-257, 2014.

[3] D. Fife, "Practical evaluation and management of atrophic acne scars: tips for the general dermatologist," J. Clin. Aesthet. Dermatol, Vol. 4(8), p. 50, 2011.

[4] C. I. Jacob, J. S. Dover, and M. S. Kaminer, "Acne scarring: a classification system and review of treatment options," J. Am. Acad. Dermatol, Vol. 45(1), PP. 109-117, 2001.

[5] C. Shen, "Protein engineering on human recombinant follistatin: enhancing pharmacokinetic characteristics for therapeutic application," J. Pharmacol. Exp. Ther, Vol. 366(2), PP. 291-302, 2018.

[6] Y. Sidis, A. Mukherjee, H. Keutmann, A. Delbaere, M. Sadatsuki, and A. Schneyer, "Biological activity of follistatin isoforms and follistatin-like-3 is dependent on differential cell surface binding and specificity for activin, myostatin, and bone morphogenetic proteins,"
Endocrinology, Vol. 147(7), PP. 3586-3597, 2006.

[7] H. Kim, S. Y. Moon, M. Y. Sohn, and W. J. Lee, "Insulin-like growth factor-1 increases the expression of inflammatory biomarkers and sebum production in cultured sebocytes," Ann. Dermatol, Vol. 29 (1), PP. 20-25, 2017.

[8] C. L. Hardy, "The activin A antagonist follistatin inhibits asthmatic airway remodelling," Thorax, Vol. 68(1), PP. 9-18, 2013.

[9] T.-X. Cong, D. Hao, X. Wen, X.-H. Li, G. He, and X. Jiang, "From pathogenesis of acne vulgaris to antiacne agents," Arch. Dermatol. Res, Vol. 2 (5), PP. 1$13,2019$.

[10]M. T. Hession and E. M. Graber, "Atrophic acne scarring: a review of treatment options," J. Clin. Aesthet. Dermatol,Vol. 8(1), p. 50, 2015.

[11]S. Buschke, "A decisive function of transforming growth factor- $\beta / \mathrm{Smad}$ signaling in tissue morphogenesis and differentiation of human $\mathrm{HaCaT}$ keratinocytes," Mol. Biol. Cell, Vol. 22(6), PP. 782794, 2011.

[12] A. J. McNairn, "TGF $\beta$ signaling regulates lipogenesis in human sebaceous glands cells," BMC Dermatol, Vol. 13(1), p. 2, 2013.

[13] S. Sanjabi, L. A. Zenewicz, M. Kamanaka, and R. A. Flavell, "Anti-inflammatory and pro-inflammatory roles of TGF- $\beta$, IL-10, and IL-22 in immunity and autoimmunity," Curr. Opin. Pharmacol,Vol. 9(4), PP. 447-453, 2009.

[14]M. Kistowska, "Propionibacterium acnes promotes Th17 and Th17/Th1 responses in acne patients," J. Invest. Dermatol, Vol. 135(1), PP. 110-118, 2015.

[15] M. P. Hedger and D. M. de Kretser, "The activins and their binding protein, follistatin-diagnostic and therapeutic targets in inflammatory disease and fibrosis," Cytokine Growth Factor Rev, Vol. 24(3), PP. 285-295, 2013.

[16]F. Aoki and I. Kojima, "Therapeutic potential of follistatin to promote tissue regeneration and prevent tissue fibrosis,” Endocr. J.;Vol.3(2), PP. 32-39, 2007.

[17] M. Wankell, "Impaired wound healing in transgenic mice overexpressing the activin antagonist follistatin in the epidermis," EMBO J,Vol. 20(19), PP. 53615372, 2001.

[18] A. A. El-Taweel, R. M. Salem, and O. S. El-Shimi, "Predictive value of serum markers for postacne scarring," J. Cosmet. Dermatol, Vol. 17(3), PP. 491494, 2018.

[19] M.-J. Chen, H.-F. Chen, S.-U. Chen, H.-N. Ho, Y.-S. Yang, and W.-S. Yang, "The relationship between follistatin and chronic low-grade inflammation in women with polycystic ovary syndrome," Fertil. Steril, Vol. 92(6), PP. 2041-2044, 2009. 